\title{
Various Types of Faults and Their Detection Techniquesin Three Phase Induction Motors Fault
}

\author{
Hayder O. Alwan,Dr. Qais S-Al-Sabbagh \\ Department of electrical EngineeringUniversity of Baghdad,Baghdad, Iraq
}

\begin{abstract}
Artificial neural networks are extensively used for speed, torque estimation, and solid state drive control in both DC and AC machines. These Artificial intelligent techniques are increasingly used for condition monitoring and fault detection of machines. this paper present an overview of researches onThree phase Induction Motors Faults Detection Using Artificial Neural Network(ANN), a general classification and brief description of the focus area for research and development in this direction are given under title of various types of faults and their detections techniques an improvement in three-phase squirrel-cage induction machine bearing, stator, eccentricity ,inter-turn, end-ring, broken-bar faults detection and diagnosis based on a neural network approach is presented .Future research directions are also highlighted.
\end{abstract}

Keywords: Faults Diagnose, Three Phase Induction Motor, ArtificialNeuralNetwork (ANN)

NomenclatureVariables:

FMain frequency

$\mathrm{f}_{\mathrm{b}}$ Broken bar faults frequency

$\mathrm{f}_{\mathrm{r}}$ Vibration Frequency (in the current Spectrum)

$\mathrm{f}_{\mathrm{y}}$ Rotational Frequency

g Input function

jOutput nodes

$\mathrm{n}_{\mathrm{d}}$ Eccentricity order

$\mathrm{N} \quad$ Number of balls

$\mathrm{P} \quad$ Pole pair

S Slip

$\mathrm{W}_{\mathrm{i}}$ Weight of input

$\mathrm{R} \quad$ Number of rotor slots

vHarmonics Index

BDBall diameter

PD Ball pitch diameter

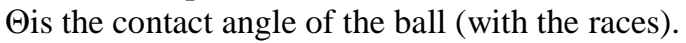

\section{INTRODUCTION}

Rotating electrical machines play a very important role in the worlds Industrial life. In petrochemical and power utilities, the failure of electrical rotating machines, such as electricmotors and generators cost millions of dinars. This is due to the loss of production, high emergency maintenance costs and lost revenues. Industry's response towards this problem of unexpected interruptions of work is by using "catch it before it fails" approaching. So, the industry started investing heavily on preventive maintenance programs, that is, detecting machine problems before they can result in catastrophic failure [1]. The oldest technique for preventive maintenance was tearing the electrical machine down and then looking at it closely. However, taking the motor out of service is costly and time consuming. This is why today's modern industry management is more interested than ever before in adopting new condition monitoring techniques, on-line or off-line, to assess and evaluate the rotating electrical machine's performance condition..

* The major faults of electrical machines can broadly be classified by the following [1]:

a) Stator faults resulting in the opening or shorteing of one coil or more of a stator phase winding.

b) Abnormal connection of the stator windings.

c) Broken rotor bar or cracked rotor end-rings.

d) Static and /or dynamic air-gap irregularities.

e) Bent shaft (akin to dynamic eccentricity) which can result in a rub between the rotor and stator, causing serious damage to stator core and windings.

g) Bearing and gearbox failures.

From the above types of faults (a) the stator winding faults, (c) the broken rotor bar and end ring faults of induction machines, (e) the eccentricity related faults and $(\mathrm{g})$ bearing faults are the most prevalent ones and thus demand special attention. Thus, these faults and their diagnosis techniques will be discussed briefly in the next chapter.

* These faults produce one or more of the symptoms as given below:[2].

a) Unbalanced air-gap voltages and line currents.

b) Increased torque pulsation's

c) Decreased average torque.

d) Increased losses and reduction in efficiency.

e) Excessive heating.

* The diagnostic methods to identify the above faults may involve several types of fields of science and technology.They were described in references $[1,2]$ as listed below 
a) Electromagnetic field monitoring, search coils, coils wound a round

motor shafts (axial flux related detection).

b) Temperature measurements.

c) Infrared recognition.

d) Radio frequency (RF) emissions monitoring.

e) Noise and vibration monitoring.

g) Acoustic noise measurements.

h) Motor current signature analysis (MCSA).

i) Model, artificial intelligence and neural network based techniques. There are different research works in the field of induction machine fault diagnosis include electrical, mechanical, and magnetic technique [2]. These techniques can be regarded as basis for developing on-line and/or off-line rotating electrical machine condition monitoring systems. Electrical and magnetic techniques include magnetic flux measurement, stator current analysis, rotor current analysis, partial discharges for evaluating stator insulation strength for high voltage motors, shaft-induced voltages, etc. Mechanical techniques include the machine bearing vibration-monitoring systems, speed fluctuation analysis of induction machines and bearing temperature measurement. Several authors have examined the effect of Bearing, stator phase and rotor eccentricity faults on machineparameters and performance. Different ways to model and to monitor the machines with Bearing, Broken rotor bar, Stator inter turn and air-gap eccentricity faults have been developed.

C.Tassoin et al. [3] have presented the detection of broken rotor bar for large induction motors by selecting the line current, voltage and speed as the monitored parameters. However, they proposed a new way for modeling the machine under broken bar .

R.R.Schoen et al. [4] have also proposed new method for induction motor fault detection by built on_line system utllizes artificial neural networks to learn the spectral characteristics of a good motor operating on_line.

S. Liling et al. [5] have reported an improved stator current based detection scheme for bearing fault in induction motors, by experiments of bearing fault then thoroughly analyzing the experiment results.

M. S. Arefeen et al. [6] presented a similar paper on the analysis of air-gap flux, current and vibration signals as a function of both static and dynamic airgap eccentricity in 3-phase induction motors. They used the same approach, the air-gap permeanceapproach, as in [2] for calculating the flux density and unbalanced magnetic forces caused by eccentricity; except that they suggested that the dynamic and static eccentricity should both be considered simultaneously and a new theoretical analysis was presented. Also, it wassuggested that in addition to monitoring the line current signature, the vibration analysis should be put forward to identify which particular form of eccentricity is dominant.
H. A. Toliyat [7] used spectrum analysis of machine line current (Motor Current Signature Anaylsis) to detect broken bar faults. He investigate the side band components, $f_{\mathrm{b}}$, around the fundamental for detecting broken bar faults.

H. A. Toliyat et al. [8] have also proposed the detection of air-gap eccentricity in induction machines by measuring the harmonic content in the machine line currents. However, they proposed a new way for modeling the machine under eccentricity. The winding function approach accounting for all the space harmonics in the machine was used to calculate all the mutual and magnetizing inductance's for the induction machine with eccentric rotors. The interest in the condition monitoring, on-line and/or off-line, of ac machines has increased tremendously in the last few years because of economic pressures, smaller profit margins and high costs of replacement and spare parts. Therefore, to achieve this goal, it is very important to be able to develop simple models for the machines under fault conditions and then analyze the effect of faults on the machines' behavior.

B.Ayhan et al. [9] described two fault-detection schemes for a broken -rotor bar fault detection with a multiple signature -processing and demonstrates that the multiple signature processing is more efficient than a signal signature processing

M. J.Devaney et al.[10] used the anlysis of the vibration signal to detect the motor Bearing faults using Fourier transform (FT) the magnitudes of the characteristics faults frequncies are compared with base-line values to detect any deterioration in bearing health.

S. Nandi et al. [11] claimed that although MCSA can detect harmonics

as potential indicators of a fault in the stator winding, it was claimed that these harmonics can be unambiguously detect at the terminal voltage .

Yazidi et al.[12] observed that the techniques relying on the stator winding current analysis are not always reliable, especially when the number of shorted turns is small compared to the to the total number of turns in a phase winding.

A. Siddique et al.[13] They their focus his review of various AI techiques to the iduction motors, more specifically to the stator winding fault detection.

X. Huang et al.[14] propose a scheme to monitor voltage and current space vectors simultaneously in order to monitor the level of air-gap eccentricity in an induction motor. An artificial neural network is used to learnthe complicated relashionship and estimate corresponding signature amplitudes overa widerange of operation conditions.

F. Filippetti et al.[15] presented an induction machine rotor fault diagnosis based on a neural network approach, after the neural network was trained using data achieved through experimental tests on healthy machines and through simulation in case of 
faulted machines, the diagnostic system was found able to distingush between "healthy"and "faulty"machines.The aim of this Paper is to:Use a combination of two techniques, namely motor current signature analysis togather with neural network to study the effect of faults .Training the neural network to simulate the effects of three types of 3-phase induction machine faults. The required training data which will be used to train the ANN are obtained pratically by the designed monitoring system. Testing or studying the effects of ( stator inter turn, end ring and eccentricity faults) by using induction machine current signature. The rest of this paper is structured as follows. Section II gives the system model and mathematical description of the eccentricity and end ring fault problem. Section III provides and analyzes some numerical simulation results. Finally, section IV concludes the paper and discusses future works.

Various Type of Faults and The Diagnosis

The history of fault diagnosis and protection is as old as the machines themselves. The manufacturers and users of electrical machines initially relied on simple over-voltage, earth-fault, ,protections such over-current etc. to ensure safe and reliable operation. However, as the tasks performed by these machine grew more and more complex; improvements were also sought in the field of fault diagnosis. It has now become very important to diagnose faults at their very inception; as unscheduled machine downtime can upset deadlines and cause heavy financial losses. The manufacturers of these machines are now interested to include diagnostic features in machine fault software to decrease machine down time and improve stability. Abnormal improvement in signal processing hardware and software has made this possible. Primarily, these techniques depend upon locating specific harmonic components in the line current, also known as motor current signal analysis (MCSA). These harmonic components are usually different for different types of faults. However with multiple faults, MCSA can become an onerous task as different types of faults and time harmonics may end up generating similar signatures.Thus other signals such as speed, torque, noise, vibration etc., are also explored for their frequency contents. Sometimes, altogether different techniques such as thermal measurements, chemical analysis, etc., are also employed to find out thenature and the degree of the fault. It is indeed evident that this area is vast in scope.[8] Several surveys have been carried out on the reliability of electrical machines.In such surveys,a large number of machine operators were usually questioned on the types and frequency of faults occuring in their plant.The largest of these surveys,carried out by the General Electric Company,was reported in an EPRI(Electric Power Research Institute)Publication(1982)and coverd about
5000 motors,approximately $97 \%$ of which were threephase cage induction motors.According to this survey,fig(1-1)presents the distribution of faults occuring in the motors surveyed.It must be noted that Fig.(1-1)provides data from machines working in many different applications and in several different branches of industry.It is known that the occurrence of any of faults types will depend heavily on specific application of the machine.For example,it has been found that in cage induction machines, the incidence of rotor cage failures can being at least as high as stator winding failures in applications where the machine is continuously being stopped and restarted under a heavy load(drilling machines in the oil and mining industries).[40].

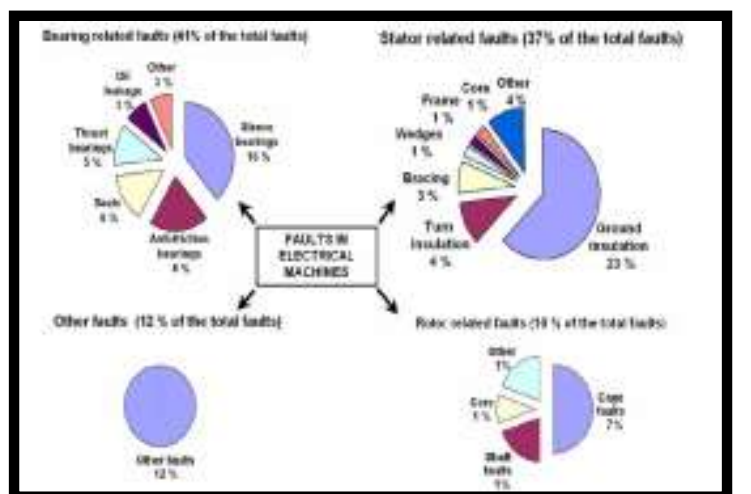

Fig(2-1) Distribution of faults EPRI 1982(Electric Power Research Institute )

Based on the work of Thorsen and Dalva (1999),Fig(1-2)is intended to highlight the failure distribution among failed components in 483 highvoltage induction motors working in the same branch of industry,i.e.the petrochemical industry.Such motors very often operate in extreme condition within offshore activities. They are often started directly online, which leads to large starting currents and torgue pulsation.these condition are harmful for the motor,weaking different machinebc omponentsv in time .comparing the results of this survey with the ones presented by EPRI(1-1),it becomes clear that the occurrence of a specific faults type

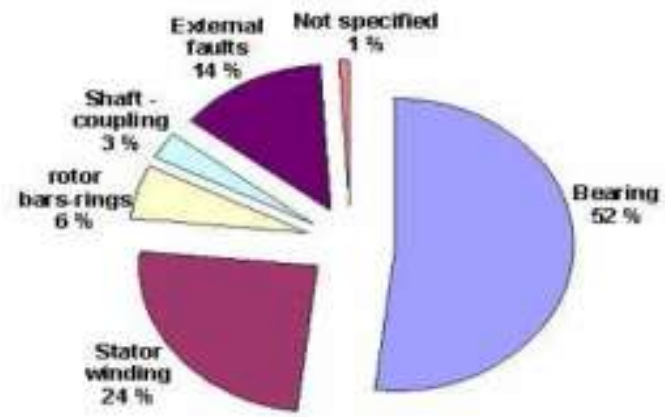

Fig(2-2) Distribution of failures among failed components for electrical machines working In the petrochemical industry (Thorsen and Dalva 1999) 
depends considerably on the specific application of the machine and on the enviroment the machine is operating in.[41].

\subsection{Various Type of Faults and Their Detection Technique}

\subsubsection{Bearing Faults:}

The majority of the electrical machines use ball or rolling element bearings. Each of these bearings consists of two rings, one inner and the other outer. A set of balls or rolling elements placed in raceways rotate inside these rings.

Even under normal operating conditions with balanced load and good alignment, fatigue failures may take place. These faults may lead to increase vibration and noise levels .Flaking or spalling of bearings might occur when fatigue causes small pieces to break loose from the bearing.

Other than the normal internal operating stresses, caused by vibration, inherent eccentricity, and bearing currents due to solid state drives, bearings can spoiled by many other external causes such as

a) Contamination and corrosion caused by pitting and sanding action of hard and abrasive minute particles or corrosive action of water, acid etc.

b) Improper lubrication; which includes both over and under lubrication causing heating and abrasion.

b) Improper Installation of bearing. By improperly forcing the bearing onto the shaft or in the housing (due to misalignment) indentations are formed in the raceways (brinelling).

Though, almost $40-50 \%$ of all motor failures are Bearing related, very little has been reported in literature regarding bearing related fault detection. Bearing faults might manifest themselves as rotor asymmetry faults [8], which are usually covered under the category of eccentricity related faults. Otherwise, the ball bearing related defects can be categorized as [1] outer bearing race defect, inner bearing race defect, ball defect and train defect.

The vibration frequencies to detect these faults are given by:

for an outer bearing race defect

$$
f_{\mathrm{v}}[\mathrm{Hz}]=(\mathrm{N} / 2) \boldsymbol{f}_{\mathrm{r}}\left[1-\mathrm{b}_{\mathrm{d}} \cos (\square) / \mathrm{b}_{\mathrm{p}}\right] ;
$$

for an inner bearing race defect

for a ball defect $(2.1)$

$$
f_{\mathrm{v}}[\mathrm{Hz}]=(\mathrm{N} / 2) \boldsymbol{f}_{\mathrm{r}}\left[1+\mathrm{b}_{\mathrm{d}} \cos (\square) / \mathrm{b}_{\mathrm{p}}\right] \text {; }
$$

for a train defect

$$
f_{\mathrm{v}}[\mathrm{Hz}]=\mathrm{b}_{\mathrm{p}} \boldsymbol{f}_{\mathrm{r}} / \mathrm{b}_{\mathrm{d}}\left\{1+\left[\mathrm{b}_{\mathrm{d}} \cos (\square) / \mathrm{b}_{\mathrm{p}}\right]^{2}\right\} ;
$$

$$
f_{\mathrm{v}}[\mathrm{Hz}]=\left(f_{\mathrm{r}} / 2\right) f_{\mathrm{r}}\left[1-\mathrm{b}_{\mathrm{d}} \cos (\square) / \mathrm{b}_{\mathrm{p}}\right] \text {; }
$$

where $\boldsymbol{f}_{\mathrm{r}}$ is the rotational frequency, $\mathbf{N}$ is the number of balls, $\mathbf{b}_{\mathbf{d}}$ and $\mathbf{b}_{\mathbf{p}}$ are the ball diameter and ball pitch diameter respectively, and $\beta$ is the contact angle of the ball (with the races).
A. Murrayet. al. [4] have shown that these vibration frequencies reflect themselves in the current spectrum as

$$
\boldsymbol{f}_{\text {bng }}=\left|\boldsymbol{f} \pm \mathbf{m} \cdot \boldsymbol{f}_{\mathbf{v}}\right|
$$

Where $\mathbf{m}=1,2,3 \ldots$ and $\boldsymbol{f}_{\mathrm{v}}$ is one of the characteristic vibration frequencies. However, the experimental results were presented for rather extensive bearing damages (such as hole in the outer race of the bearing; brinelling induced by a vibration table).

Da-Ming et.al. [5] have reported of an adaptive, statistical time frequency method for detection of bearing faults. Experiments were conducted on defective bearings with scratches on the outer races and bearing balls and cage defects .It has been claimed that all defective measurements were correctly classified as defective.

However, the detection procedure required extensive training for feature extraction.

\subsubsection{Stator Faults:}

These faults are usually related to insulation failure. In common parlance they are generally known as Phase-to-ground or phase-to-phase faults. It is believed that these faults start as undetected turn-toturn faults that finally grow and culminate into major ones [8]. Almost 30-40\% of all reported induction motor failures falls in this category.

\section{* Stator insulation can fail due to several} reasons. Primary among these are

a) High stator core or winding temperatures.

b) Slack core lamination, slot wedges and joints.

c) Loose bracing for end winding.

d) Contamination due to oil, moisture and dirt.

e) Short circuit or starting stresses.

f) Electrical discharges.

g) Leakage in cooling systems.

There are a number of techniques to detect these faults. Penman et. al. [11] were able to detect turn to turn faults by analyzing the axial flux component of the machine using a large coil wound concentrically around the shaft of the machine. Even the fault position could be detected by mounting four coils symmetrically in the four quadrants of the motor at a radius of about half the distance from the shaft to the stator end winding. The frequency components to be detected in the axial flux component is given by,

$(\mathbf{k} \pm \mathbf{n}(\mathbf{1 - s}) / \mathbf{p}) \boldsymbol{f}$

where pis the number of pole pairs, $f$ is the mains frequency, $k=\mathbf{1 , 3}$ and $n=\mathbf{1 , 2 , 3}, \ldots,(\mathbf{2 p - 1})$ and $\mathbf{s}$ isthe slip.

Toliyat and Lipo [12] have shown both through modeling and experimentation that these faults result in asymmetry in the machine impedance causing the machine to draw unbalance phase currents. 
This is the result of negative sequence currents flowing in the line as also have been shown in [8]. However, negative sequence currents can also be caused by voltage unbalance, machine saturation etc.

\section{* Short circuit in stator winding}

In large generators and motors in power plants, the stator and rotor winding insulation is exposed to a combination of thermal,electrical,vibration, thermo-mechanical,and environmental stresses during operation.In the $10 \mathrm{~g}$ term,the multiple stresses cause ageing,which finally leads to insulation breakdown.For this reason, it is important to estimate the remaining insulation integrity of the winding after a period of operating time.

Deterioration of the winding insulation usually beings as an inter-turn fault involving a few turns of the winding.A turn fault in the stator winding of an electrical machine causes a large circulating current to flow in the shorted turns.Such a circulating current is of the magnitude of twice the locked rotor current;it causes severe localised heating and sustains favourable conditions for the fault to rapidly spread to a larger section of the winding[42].Another fault associated with the stator winding is called"singlephasing".In this case,one supply line or phase winding becomes open-circuited.The resulting motor connection has a line voltage directly across two phases(assuming a"star"connected machine) which is equivalent to a single-phase circuit. The effect of an insulation fault between turns is to eliminate a turn or group of turns from the stator winding. This will be of little consequence but it will be quantifiable in the flux distribution in the air-gab .[11]

Fig.2-3 shows an inter-turn short circuit between two points, $a$ and b,of a complete stator winding. The path to the circulating current between these points is closed and the path $\mathrm{A}-\mathrm{A}^{\prime}$ can be expanded into two independent circuits.Fig. 2.3 shows that the two currents, the phase current and the current which flows in the short circuited part,produce opposite MMFs.Therefore,inter-turn short circuits have a cumulative effect in decreasing the MMF in the vicinity of the short - circuited turn(s).Firstly, when a short circuit occurs, the phase widing has less turns and,therefore,less MMF.Secondly,the short-circuit current MMF is opposite the MMF of the phase winding. The circulating current Ic is a result of the galvanic contact between points a and b but also due to the contribution brought by the transformer effect or mutual induction.

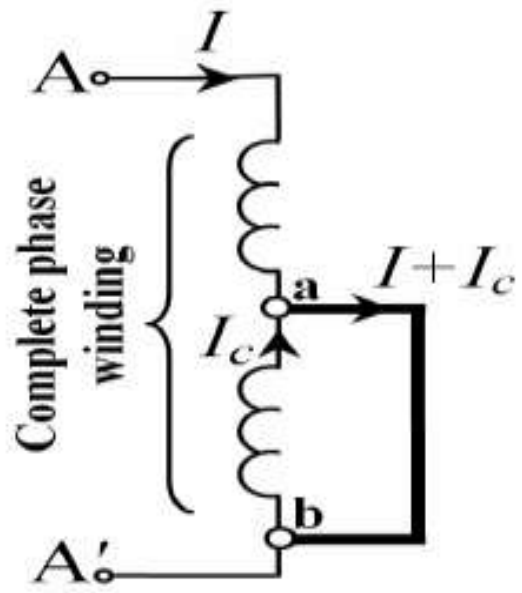

Fig(2-3) Iner-turn short circuit

\subsubsection{Broken Rotor Bar and End Ring faults:}

Unlike stator design, cage rotor design and manufacturing has undergone little change over the years. As a result rotor failures now account for around $5-10 \%$ of total induction motor failures [2],[8].

Cage rotors are basically of two types: cast and fabricated. Previously, cast rotors were only used in small machines. However, with the advent of cast ducted rotors; casting technology can be used even for the rotors of machines in the range of $3000 \mathrm{KW}$. Fabricated rotors are generally found in larger or special application machines. Cast rotors though more rugged than the fabricated type,can almost never be repaired once faults like cracked or broken rotor bars develop in them. when there is a broken bar, no current flows throught the broken rotor bar, thus no magnetic flux is generated around the broken rotor bar as is illustrated in Fig(2-4) this generates an asymmetry in the rotor magnetic field by yielding a non-zero backward rotating field .It has to be noted that for a symmetrical rotor with no broken bar the resultant of backword rotating fields is zero[39].this non-zero backward -rotating field rotates at slip-frequency speed with respect to the rotor .and induces harmonic currents in the stator windings, which are superimposed on the stator winding currents[39].these superimposed harmoic are used as signatures of broken rotor bar faults in motor current signature analysis(MCSA) techniques.

The broken rotor bar faults can be simulated using the squirrel-cage iduction motor mathmatical model Fig.(2-5), it is seen that one branches that is composed of a resistor and an inductor which represents a rotor bar is removed from the rotor cage electrical model to simulate a broken bar. 


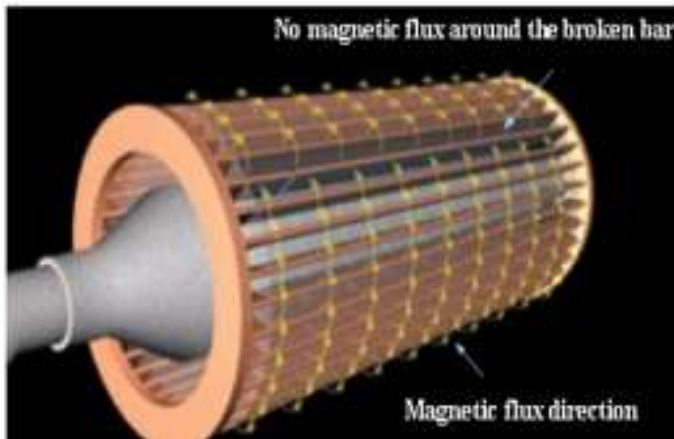

Fig(2-4)illustration of rotor bar currents and magnetic flux in the existence of a broken rotor bar.

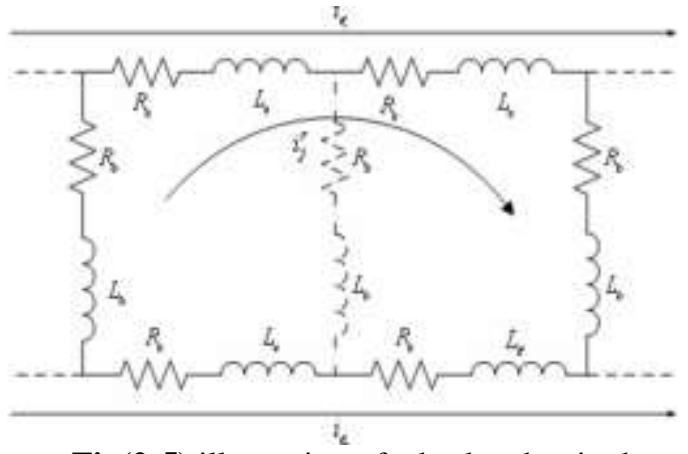

Fig(2-5) illustration of a broken bar in the mathematical model.

* There are several reasons for rotor bar and end ring breakage,they can be caused by

a) Thermal stresses due to thermal overload and unbalance, hot Spots or excessive losses, sparking (mainly fabricated rotors).

b) Magnetic stresses caused by electromagnetic forces, unbalanced magnetic pull, electromagnetic noise and vibration.

c) Dynamic stresses arising from shaft torque, centrifugal forces and cyclic stresses.

d) Environmental stresses caused by for example contamination and abrasionof rotor material due to chemicals or moisture.

d) Mechanical stresses due to loose laminations, fatigued parts, bearing failure.

Filippetti [3], H. A. Toliyat [7] used spectrum analysis of machine line current (MCSA) to detect broken bar faults. They investigate the side band frequency components, $\boldsymbol{f}_{\mathrm{b}}$, around the fundamental for detecting broken bar faults.

$$
\underset{(2.4)}{\boldsymbol{f}_{\mathbf{b}=}(\mathbf{1} \pm \mathbf{2 s}) \boldsymbol{f}}
$$

While the lower side band is specifically due to broken bar, the upper side band is due to consequent speed oscillation. In fact [13] shows that broken bars actually give rise to a sequence of such side bands given by

$$
f_{b=}\left(1 \pm 2 k_{1} s\right) f \quad, k_{1}=1,2,3 \ldots
$$

and is depicted conceptually in fig( 2.5).

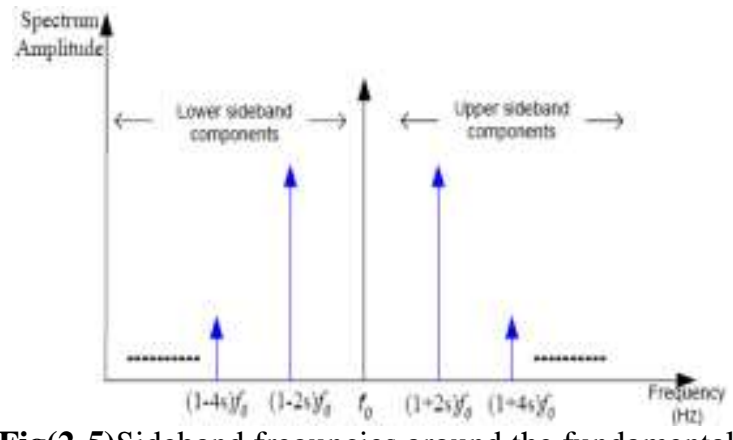

Fig(2-5)Sideband freguncies around the fundamental line freguency.

Fig(2-5) shows the freguency compoets specific to abroken rotor barfaults, which is given in eguation (2.5) for $\mathrm{k}=1$ and 2.these freguencies are located around the fundamental line freguency and called as lowerd sideband and upper sideband components, as indicated in Fig(2-5).

The motor-load inertia also affects the magnitude of this side band. Other spectral components that can be observed in the stator line current is given by [3] and [7].

$$
f_{\mathrm{b}=}\left[\left(\mathrm{k}_{1} / \mathbf{p}\right)(1-\mathrm{s}) \pm \mathrm{s} f\right]
$$

Where, $\boldsymbol{f}_{\mathbf{b}}=$ detectable broken bar frequencies; $\mathbf{k}_{\mathbf{1}}=$ $\mathbf{1 , 2 , 3}, \ldots$ Elkasabgy [14] has also shown that broken bar faults can also be detected by time and frequency domain analysis of induced voltages in search coils placed internally around stator tooth tip and yoke and externally on motor frame.

The frequency components are given by (2.6) with $\mathbf{k}_{\mathbf{1}}=\mathbf{1}$. Torque and speed signals also contain $\mathbf{2 s f}$ and 4sf frequency components with broken rotor bars [13],[14].

detection of these faults are also possible by frequency domain analysis of shaft flux or more generally axial leakage flux which is monitored by using an external search coil wound around the shaft of a machine.

The frequency components are still given by (2.6) with $\mathrm{k}=1,2,3$. Modeling of rotor bar and end ring faults have been described in [8]. Broken bar detection using state and parameter estimation techniques have also been reported [23]. However the current spectrum and the parameter estimation approach have been compared and the former has been found more efficient [24].

Modeling of rotor bar and end ring faults have been described in [12]. 


\subsubsection{Eccentricity Related Faults:}

Machine eccentricity is the condition of unequal air-gap that exists between the stator and rotor [1-8]. When eccentricity becomes large, the resulting unbalanced radial forces (also known as unbalanced magnetic pull or UMP) can cause stator to rotor rub, and this can result in the damage of the stator and rotor.

There are two types of air-gap eccentricity: the static air-gap eccentricity and the dynamic air gap eccentricity(Fig.2-6). In the case of the static air-gap eccentricity, the position of the minimal radial air-gap length is fixed in space. Static eccentricity may be caused by the ovality of the stator core or by the incorrect positioning of the rotor or stator at the commissioning stage. If the rotor-shaft assembly is sufficiently stiff, the level of static eccentricity does not change.

In case of dynamic eccentricity, the center of the rotor is not at the center of the rotation and the position of minimum air-gap rotates with the rotor. This misalignment may be caused due to several factors such as a bent rotor shaft, bearing wear or misalignment, mechanical resonance at critical speed, etc.

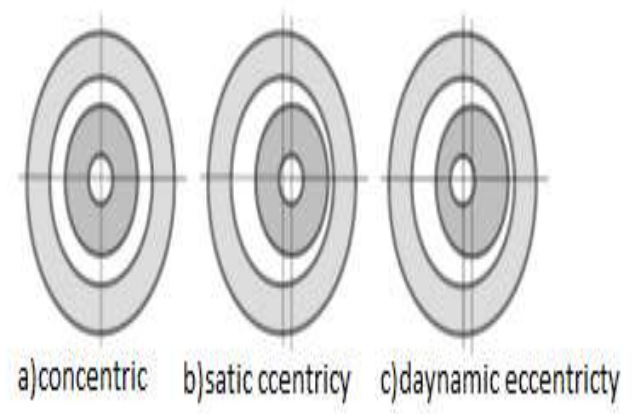

Fig(2-6) Eccentricity types

In reality both static and dynamic eccentricities tend to co-exist.An inherent level of static eccentricity exists even in newly manufactured machines due to manufacturing and assembly method, as has been reported by Dorrell [17]. This causes a steady unbalanced magnetic pull (UMP) in one direction. With usage, this may lead to bent rotor shaft, bearing wear and tear etc.

This might result in some degree of dynamic eccentricity. Unless detected early, these effects may snowball into stator to rotor hub causing a major breakdown of the machine [18].

The presence of static and dynamic eccentricity can be detected using MCSA [1],[17]. The equation describing the frequency components of interest is

$f\left[\left(\mathbf{k}_{1} \mathbf{R} \pm \mathbf{n}_{\mathrm{d}}\right)(\mathbf{1}-\mathbf{s}) / \mathbf{p} \pm \mathbf{v}\right]$

(2.7) where $\mathbf{n}_{\mathrm{d}}=\mathbf{0}$ in case of static eccentricity, and $\mathbf{n}_{\mathbf{d}}=\mathbf{1 , 2 , 3}, \ldots$ in case of dynamic eccentricity $\left(\mathbf{n}_{\mathbf{d}}\right.$ is known as eccentricity order), $\boldsymbol{f}$ is the fundamental supply frequency, $\mathbf{R}$ is the number of rotor slots, sis the slip, pis the number of pole pairs, $\mathbf{k}_{\mathbf{1}}$ is any integer, and $\mathbf{v}$ is the order of the stator time harmonics that are present in the power supply driving the motor ( $v= \pm 1, \pm 3, \pm 5$, etc . ). In case

one of these harmonics is a multiple of three, it may not exist theoretically in the line current of a balanced three phase machine.

However it has been shown by Nandi [19], Ferrah [20] that only a particular combination of machine poles and rotor slot number will give rise to significant only static or only dynamic eccentricity related components.However, if both static and dynamic eccentricities exist together, low frequency components near the fundamental [21], [22] given by

\section{$\boldsymbol{f}_{\mathbf{1}}=\left|\boldsymbol{f} \pm \mathbf{k}_{\mathbf{1}} \boldsymbol{f}_{\mathrm{r}}\right| \quad \mathbf{k}_{\mathbf{1}}=\mathbf{1 , 2 , 3} \ldots \quad(2.8)$}

can also be detected. Mixed eccentricity also give rise to high frequency components as described by (2.7). Modeling based approaches to detect eccentricity related components in line current have been described in [19],[21]. The simulation results obtained through the models are also well supported by permeance analysis and experimental results.

Vibration signals can also be monitored to detect eccentricity-related faults. The high frequency vibration components for static or dynamic eccentricity are given by [8] using an equation similar to (2.7) (only the values of $\mathbf{n}_{\mathbf{d}}$ and $\mathbf{v}$ are different). In case of mixed eccentricity, the low frequency stator vibration components are given by

$\boldsymbol{f}_{\mathrm{v}}=\mathbf{2} \boldsymbol{f} \pm \boldsymbol{f}_{\mathrm{r}}(2.9)$.

\subsection{Analysis of Acquired Data (Software Structure)}

The acquired data is stored in the computer, from which it can be retrieved for later processing. The processing involved several different routines each written for a specific task. The first task is to sort the data from one input channel to separate files then these data will load to the program to draw it as line current with time for each type of the five faults at no-load, half-load and full-load . It circuit important that the measured value of current at each case should be given to the program. The Fast Fourier Transform (FFT) is then used by the same program as shown in Fig. (2-7). 

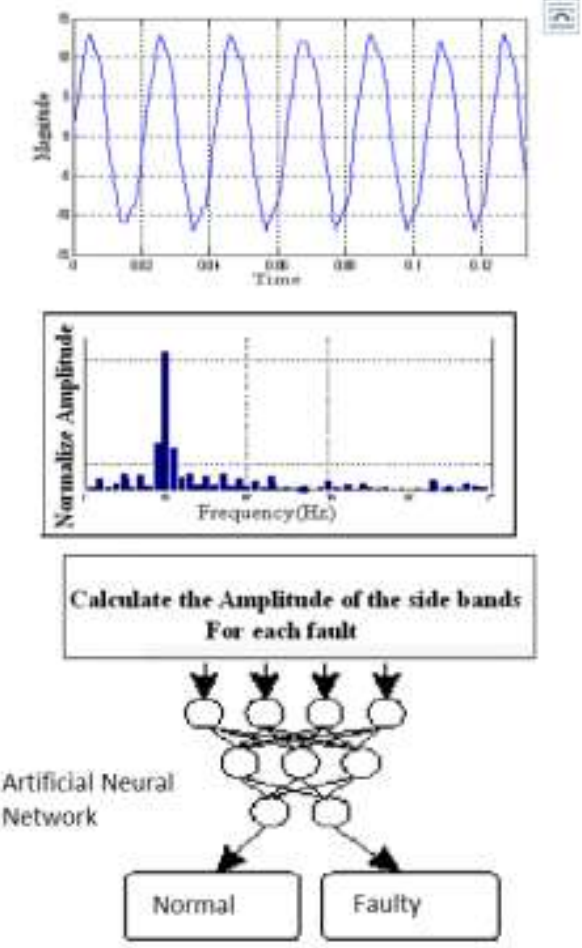

Fig 2-7. Intelligent Diagnose of Induction motor Fault

After compute the sampling time and sampling frequency to find the magnitude of the side bands frequencies and their amplitude. It is worth mentioning that the Signal processing techniques are applied to the measured sensor signals in order to generate features or parameters (e.g. amplitudes of frequency components associated with faults) which are sensitive to the presence or absence of specific faults. The output from the FFT is then scanned to determine if frequency components that characterize a particular fault type are present.

\section{Conclusion And Future Work}

The work reported in this paper has involved designing and building a motor monitoring system using an Aritificial neural network for fault detction of three phase induction motor .To accomplish this, a hardware system was designed and built to acquire three-phase stator current and speed from a $(2.2 \mathrm{kw})$ squirrel-cage induction motor. The ability of the phase current to detect specific fault was tested, sincemonitoring this parameter is the most convenient and cheapest way to sense a fault. it was clear that The sideband frequencies are function of the slip, so they are changing with the speed (that change with the load) .

From the sideband frequencies calculated in the tables(1,2 and 3) it's found that the distance of the positive and negative from the fundamental increased with increasing of the load, and the same for different values of $\mathrm{k} / \mathrm{p}$ and for all types of faults. From the reported work, the disadvantage of most ANN's are their inability to respond to previously unseen conditions. Therefore, if there is an occurance of a new fault that the network doesn't been train to recognize ,and the fault may be misdiagnosed which produce weak output results. The number of selected input channels of data acquisition circuit used in this work was two (one for current and the other for tachometer), these slected chanals may increase to four depend on the types of data needed to investigated.

\section{REFERENCES}

[1]. N. A .Al-Nuaim, H. A.Toliyat"A Novel Method For Modeling Dynamic Air-Gap Eccentricity in Synchronous Machines Based on Modified Winding Function Theory" IEEE Transaction on Energy Conversion,Vol.13, 2, June 1998.

[2]. H. A. Toliyat and M. A. Haji"Pattern Recognition-Technique for Induction Machines Rotor Fault Detection Eccentricity and Broken Bar Fault" Department of Electrical Engineering Texas A\&M IEEE Transactions on Energy Conversion, Vol 2001.

[3]. F. Filippetti, G. Franceschini, C. Tassoin "Neural Networks Aided On-line Diagnostics of Induction Motor Rotor Faults" presented at IEEE Transactions on Industry Applications, VOL.31 NO.4, and July/August 1995.

[4]. R.R.Schoen,T.G.Habetler“ An Unsupervised,On_Line System for Induction Motor Fault Detection Using Stator Current Monitoring " IEEE Georgia Institute of Technology 1994.

[5]. S. Liling, X. Boqiang "An Improvement of Stator Current Based Detection of Bearing Fault in Induction Motors" Proceeding of School of Electriccal Engineering, North China Electric Power University (Baoding). 2007.

[6]. M. S. Arefeen, A. G. Parlos and H. A. Toliyat "A Method for DynamicSimulation Detection of Air-gap Eccentricity In Induction Machines" Presented at IEEE Transactions on Industry Applications, Vol.26 NO.54, June 1995.

[7]. H. A. Toliyat, S. Nandi and A. D. Minassians "A Novel Approach for Broken Rotor Bar Detection in Cage Induction Motors" IEEE Transaction on Industry Application,Vol.35, No.5, September/October 1999

[8]. H. A. Toliyat and S.Nandi“"Condition Monitoring and Fault Diagnosis of Electrical Motors -A Review" IEEE 
Transactions on Energy Conversion, Vol.20 NO.4, December 2005.

[9]. B. Ayhan and M.Yuen"Multiple Discriminant Analysis and Neural-Network -Based Monolith and Partition FaultDetection Schemes For Broken Rotor Bar in Induction Motors "IEEE Transactions on Industrial Electronics.Vol.53 NO.4.August 2006.

[10]. M. J. Devaney and L. Eren"Monitoring an Induction Motor's Current and Detecting Bearing Failure" IEEE Instrumentation Measurement Magazine, December 2004.

[11]. S.Nandi, H.A.Toliyat, "Novel Frequency Domain_ Based Technique to Detect Incipient Stator Intertern Faults in Induction Machines", The 2002 IEEE Industry Application Society Conference, The $35^{\text {th }}$ IAS Annual Meeting, Rome, ItalyVol, 38.No.1, January/February 2002.

[12]. A.Yazidi,D.Thailly,H.Henao,R.Romary,G.A. Capolino,J.F.Brudny,2004“'Detection of Stator Short-Circuit in Induction Machines Using an External Leakage Flux Senser'IEEE International Conference on Industrial Technology- ICIT'Dec.8-10,2004, Hammamet, Tunisia, Vol.1,pp. 166-169.

[13]. A.Siddique,G.S.Yadava,B.Singh,2003,"Appli cations of Artificial Intelligence Techniques For Induction Machine Stator Faut Diagnostics:Review", $4^{\text {th }}$ IEEE International Symposium on Diagnostics for Electric Machines ,Power Electronics and Drives-SDEMPED,03,Atlanta-USA,Aug.2426,2003,pp.29-34.

[14]. X.Huang, R.G.Harley, 2004,"Detection of Roto Eccentrici-ty Faults Inclosed-Loop DriveConnected Induction Motors Using an Artificial Neural ", IEEE $35^{\text {th }}$ Annual Power Electronics Specialists Conference-PESC, Aachen, Germany, June 2004, 20-25, Vol.2, pp. 913-918.

[15]. F.Filippetti, G. Franceschini, C.Tassoni"Neural Networks Aided On-Line Diagnostics of Induction Motor Rotor Faults", IEEE Transaction on industry Applications, Vol.31, Issue 4, pp.892-899. 2005.

[16]. N. M. Elkasabgy, A. R. Eastham, G. E. Dawson, "Detection of brok bars in the cage rotor on an induction machine", IEEE Trans. Ind Applns., vol. IA-22, no.6, pp. 165-171, Jan./Feb. 1992

[17]. D. G. Dorrell, W. T. Thomson and S. Roach, "Analysis of airgap flux, current, Vibration signals as a function of the combination of static and dynamic airgap eccentricity in 3- phase induction motors", IEEE Trans. Ind. Apples., vol. 33, No.1,pp. 24-34, 1997.

[18]. A. Barbour and W.T. Thomson, "Finite element study of rotor slot designs with respect to current monitoring for detecting static airgap eccentricity in squirrel-cage induction motor," IEEE-IAS annual meeting conference recordings, pp. 112-119, New Orleans, Louisiana,Oct.5-8, 1997.

[19]. S. Nandi and H. A. Toliyat, "Detection of Rotor Slot and OtherEccentricity Related harmonics In a three Phase Induction Motor WithDifferent Rotor Cages." IEEE Trans Energy Convers., vol.16,no.3,pp.253260,Sep.2001.

[20]. A. Ferrah, P.J. Hogben-Liang, K. J. Bradley, G.M. Asher, M. S.Woolfson,"The effect of rotor design of sensorless speed estimation using rotor slot harmonics identified by adaptive digital filtering using the maximum like lihood approach," IEEE-IAS annual meetingconference recordings,pp.128-135, New Orleans, Louisiana, Oct. 5-8, 1997.

[21]. S. Nandi, RajMohan Bharadwaj, H.A. Toliyat, A.G. Parlos, "Performance analysis of a three phase induction motor under incipient mixed eccentricity condition", IEEE Trans.,Energy Convers., vol.17.no.3.pp392-399.Sep.2002 .

[22]. D. G. Dorrell, W. T. Thomson and S. Roach, "Analysis of airgap flux,current, vibration signals as a function of the combination of static and dynamic airgap eccentricity in 3phase induction motors", IEEE Trans.

[23]. Ind. Applns.n., vol. 33, No.1, pp. 24-34, 1997.

[24]. K.R.Cho.J.H.Lang.and S.D.Umans, "Detection of broken rotor bars ininduction motors using state and parameter estimation, " IEEE Trans.Ind.Appl.,vol.28,no.3,pp.702709.May/Jun.1992

[25]. F.Filippetti,G.Franceschini,C.Tassaoni, and P.Vas, "Broken bar detection in induction machines;comparison between current spectrum approach and parameter estimation approach, " in Proc.IEEE Industry Application Soc.Annual Meeting Conf.,vol.1,Denver,1994,pp.95-102

[26]. Zurada J. M., "Introduction to Artificial Neural Systems", JAICO Publishing House, 1997.

[27]. HayKin Simon, "Neural network a Comprehensive foundation",prentice Hall,1999.

[28]. Jian Y.ONY Chen, Z. Chen, S. Xu,Y. Lu , Jzhoy, "BP algorithm with

[29]. Chaos in MLP neural networks", international Conference on neural 
[30]. networks and Brain Proceedings, Oct. 2730,1998 Geijing, China.

[31]. Funahashi Ken-ichi, "Multilayer neural network and Bayes decision

[32]. theory “, Neural Networks vol.11, No.2, March 1998, pp.209-213.

[33]. Chitra S. P., "Use Neural Networks for Problem Solving", Chemical Engineering Progress, April 1993.

[34]. Davalo E., and Naim P., "Neural Networks", Machllan, 1991.

[35]. Fausett L., "Fundamentals of Neural Networks, Architectures, Algorithms, And Applications", Prentice Hall International, Inc., 1994.

[36]. Hadi A. S., "Hybrid Method (GA - BP) for Designing And Learning The Error BackPropagation Network with Principle of Weight Decay", M. Sc. Thesis, Department of Computer Science, Science College, University of Babylon 2000.

[37]. Huang S., Huang Y., "Learning Algorithm for Perceptrons Using Back-Propagation with selective Updates", IEEE Control System Magazine, P:56-60, 1990.

[38]. Jones W. P., and Hoskins J., "Back Propagation - A Generalized Delta Learning Rule.”, BYTE Magazine, P:135, October 1987.

[39]. Shamil K. Mansour “ PC Basic SCADA system for PVPS", M.Sc. thesis, University of Technology, 1998.

[40]. Alexej V. Barkov, "The Capabilities of the new generation of the Monitoring and Diagnostic system" Published in the magazine

[41]. "Metallurg", VAST, Inc., No.11, 1998.

[42]. Alexej V. Barkov, "Development of Condition Diagnostics in Russia

[43]. Using Vibration" Vibro Acoustical Systems and Technologies (VAST,

[44]. Inc.), 22,Rosenshtenia, St. Petersburg, 198095, Russia.

[45]. Yishay $M$ and Sigal S. "Implementation Issues in the Fourier Transfor Algorithm" In Annual Workshop on Computational Learning Theory, pages 62-70 ,July 1992.

[46]. J.F Bangura,N.A.Demerdash, . "Diagnosis and Characterization of Effect of Broke Bars and connectors in squrrel-cage induction motors by a time -stepping coupling finite element state space modeling approach"IEEE Trans.EnergyConversion,vol.14,no.6,pp.1167 -1176,dec1999.

[47]. Marian Dumitru Negrea,. "Electromagnetic flux monitoring for detecting faults in electrical machines"Dissertation for the doctorof science in Technology ,Helsinki
Uinversity of Technology, on the $29^{\text {th }}$ of Novemer 2006.

[48]. Thorsen,O.V.,Dalva,M.,1999, "Failure identification and analysis for high voltage induction motors in the petrochemical industry"IEEE Transaction on Industry Application,Vol.35,No.4,pp.810-818.

[49]. Kliman,G.B.,Premerlani,W.J.,Koegl,R.A.,Ho eweler,D.,1996, "A new approach to on-line fault detection in ac motor"The 1996 IEEE Industry Applications Society Conference:The $30^{\text {th }} \quad$ IAS Annual Meeting,San Diego-CA,USA,Oct.610,1996,pp.687-693.

[50]. Nandi,S.Toliyat,H.A.,2000, "Novel frequency domain based technique to detect incipient stator inter-turn faults in induction machines",The 2000 IEEE Industry Application Society Conference, The $35^{\text {th }}$ IAS Annual Meeting,Rome,ItalyVol,Oct.812,2000,pp.367-374. 